\title{
Existence of mandibular directional asymmetry in the European wild boar (Sus scrofa Linnaeus, 1758)
}

\author{
PARÉS-CASANOVA, P. M.*
}

Department of Animal Production, University of Lleida, Av. Alcalde Rovira Roure, 191, 25198 Lleida, Catalunya, Spain *E-mail: peremiquelp@prodan.udl.cat

\begin{abstract}
Introduction and material and methods. We studied a sample of 37 dentulous dry mandibles from European wild board (Sus scrofa) and compared both the right and left sides in their dorsal aspect. To study the influence of age, the samples were grouped according to dental status: "subadults" (erupting 3rd M, n=22) and "adults" (fully erupted $3 \mathrm{rd} M, \mathrm{n}=15$ ). Individual levels of asymmetry were analysed from $\mathrm{x}$ - and $\mathrm{y}$-coordinates of the 16 landmarks on the dorsal aspect of the mandible. Results. The analysis separated directional asymmetry (one side of the body with a larger character value than the other) and fluctuating asymmetry (small random deviations from perfect symmetry), which were both found to be significant. Conclusion. The condylar ramus was the most asymmetric structure for both age groups.
\end{abstract}

Keywords: fluctuating asymmetry, geometric morphometrics, mandible, skull, symmetry.

\section{Introduction}

Developmental instability arises from genetic or environmental stressors that disturb the normal developmental pathways of different continuous characters, producing developmental noise, which is commonly measured as fluctuating asymmetry (FA) in phenotypic traits (VAN VALEN, 1962; PALMER and STROBECK, 1986; LEAMY and KLINGENBERG, 2005). FA is the variance in subtle differences between the left and right sides in bilaterally symmetrical organisms or parts of them, providing a measure of how well an individual can buffer its development against internal genetic and external environmental stress during ontogeny (VAN VALEN, 1962).

The statistical properties of geometric morphometrics (GM) are superior to those of distance-based or angle-based methods (ROHLF, 2006, 2007), with the supply graphics being far more legible and interpretable to the biologist. The method of GM, which is based on the study of landmarks, has made it easier to parameterise shape in this way, visualise changes in shape and test hypotheses statistically. Thus, they are commonly used in morphometric studies.

Analyses of symmetry consider the left and right sides separately, but it must also contain additional information on the arrangement of the two halves relative to each other (SOLON, TORRES and DEMAYO, 2012). Variation among individuals is analysed using the averages of the left and right configurations. Asymmetry is then measured from the differences in configurations on the left and right sides of each individual (KLINGENBERG and SAVRIAMA, 2002). This research aimed to determine the degree of asymmetries between the hemimandibles in wild boar (Sus scrofa Linnaeus, 1758) and whether they were due to fluctuating morphological asymmetry, and if so, whether they were functional or mechanical asymmetry.

\section{Materials and Methods}

We studied a sample of 37 dentulous dry mandibles (os dentale) from European wild board (Sus scrofa), fully preserved and collected from a vulture feeding point. The animals had been hunted and their corpses deposited there. The sex of these samples was unknown. The mandibles were disarticulated and the skulls were not studied. These samples were subdivided into 3 age groups, according to the $2^{\text {nd }}$ and $3^{\text {rd }}$ molar $(M)$ eruption: only $2^{\text {nd }} M$ ("young", $n=3$ ), erupting $3^{\text {rd }} M$ (“immature", $n=19$ ) and fully erupted $3^{\text {rd }} M$ (complete dentition, "adult", $\mathrm{n}=15$ ).

Image capture was performed with a Nikon ${ }^{\circledR}$ D70 digital camera (image resolution of 2,240 x 1,488 pixels) equipped with a Nikon AF Nikkor ${ }^{\circledR} 28-200 \mathrm{~mm}$ telephoto lens. The focal axis of the camera was parallel to the horizontal plane of reference and centred on the dorsal aspect of each mandible. A ruler was used in this process (interval $50 \mathrm{~mm}$ ). Sixteen landmarks were plotted on the mandible in order to describe the size and shape variations, producing a set of 32 raw coordinates for each specimen. Fourteen of these landmarks were topologically equivalent. Figure 1 shows the location of the landmarks. "Nomina Anatomica Veterinaria" (INTERNATIONAL..., 2005) and Von Den Driesch (1976) were used to guide the spelling of the anatomical and zoological terms in this investigation.

Shape variables were obtained as linear combinations of the original landmark coordinates after standardising size and removing artefactual variation due to different positions of the specimens in the process of data collection (generalised Procrustes analysis). Landmarks were digitised using tpsDig 2.04 (F. J. Rohlf, life.bio.sunysb.edu/ee/rohlf/software. html). Landmark positions were converted into scaled $\mathrm{x}$ and $\mathrm{y}$ coordinates using CoordGen6f (H. D. Sheets, www.canisius. edu/sheets). To estimate the amount of measurement error due to digitising, duplicated measurements were taken for all 
samples by the second author (MC), and a Procrustes analysis of variance (ANOVA) was carried out. As developmental integration in this study was assessed by investigating covariation in the patterns of asymmetry, we needed to make sure that measurement error due to digitising was negligible compared to biological shape and size variation. Size was computed as the Centroid Size (CS), which corresponds to the sum of the squared distances from the landmarks to the centroid of configuration (BOOKSTEIN, 1991). CS was extracted using Coord Gen6f (H. D. Sheets, www.canisius. edu/sheets).

\subsection{Size and shape comparison}

Size and shape comparisons between the three age groups were performed by means of a one-way NPMANOVA using Mahalanobis distance and Bonferroni-corrected values, with 9,999 permutations.

\subsection{Investigation of symmetry}

An alternative approach for quantifying the different components of variation, which is Procrustes ANOVA (KLINGENBERG and McINTYRE, 1998), was also used. The ANOVA approach was originally developed for linear measurements of bilaterally symmetrical structures and was a two-factor, mixed-model ANOVA design containing individuals and sides as the factors (LEAMY, 1984; PALMER and STROBECK, 1986). Directional asymmetry (DA, "sides", one side is systematically different from the other one), fluctuating asymmetry (FA, "individual $\mathrm{x}$ side interaction", small random deviations from perfect symmetry), and their respective error were included as effects. In summary, the magnitude of mandible asymmetry for each respondent was measured following three steps. In the first step, reflected copies of each landmark were generated by

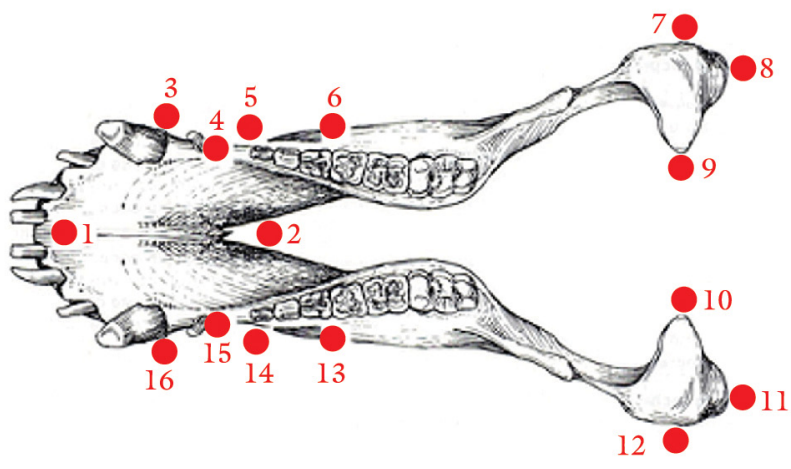

Figure 1. Designated landmarks for GM analysis of the mandible (dorsal aspect). The references are explained in the text. reversing the side of its $\mathrm{x}$-coordinate. Then, the Procrustes average of each mandible was defined as the middle of the line passing between the original landmark and the reflected copy of the corresponding landmark. The new mandible shape created by connecting these average landmarks was perfectly symmetrical. Lastly, the asymmetry of each mandible was calculated as the difference between the original and the mirror configurations or, equivalently, the landmark deviations of the original configuration from the average landmarks. Our configuration protocol considered 14 paired landmarks to estimate the level of asymmetry (e.g., 3-16, 4-15, 5-14, 6-13, 7-12, 8-11 and 9-10). The assumption of isotropic variation at each landmark was questionable because the scatters of landmark positions around the overall consensus were not circular. Consequently, MANOVA tests were carried out. Since it avoids the assumption of equal and isotropic variation at each landmark and thus takes into account the structure of shape variation, the MANOVA test has a higher statistical power. The statistical significance of the relationship between the shape scores and the centroid sizes was assessed by a permutation test with 10,000 rounds of random permutations (e.g., SAVRIAMA, NEUSTUPA and KLINGENBERG, 2010).

The analyses were carried out in: (1) PAST"Paleontological Statistics Software Package for Education and Data Analysis" (HAMMER, HARPER and RYAN, 2001); (2) SAGE v. 1.05 (MARQUEZ, 2008); and (3) Morpho J (KLINGENBERG, 2011).

\section{Results}

\subsection{Age dimorphism}

As the general shape appeared different between the adults and the others $(\mathrm{p}<0.001)$, we pooled the "young" and "immature" into one group ("subadults") and the "adults" into another for all subsequent analyses. The hemimandibles did not differ in size between the right and left sides, regardless of age $(\mathrm{p}=0.828)$. This indicates that the hemimandibles developed similarly in size on each side.

For shape, the mean squares for individual, side and asymmetry between the sides (the side $\mathrm{x}$ individual interaction) exceeded the mean squares of the error $(\mathrm{p}<<0.001 ;$ Table 1).

\subsection{Principal component analysis}

For the symmetry analysis using principal components (PCs) for "subadults", the first component (PCl) accounted for $42.8 \%$ of the total variance. The first three components accounted for $88 \%$ of the total variance. For "adults", PCl accounted for $62.9 \%$ of the total variance and the first three

Table 1. Procrustes analysis of the amount of shape variation attributable to different sources, for all the studied hemimandibles, which were digitised twice. The measurement error also took into account the digitising error. Sums of squares and mean squares in units of squared Procrustes distance.

\begin{tabular}{lcccr}
\hline \multicolumn{1}{c}{ Source } & $\begin{array}{c}\text { Sums } \\
\text { of squares }\end{array}$ & Mean squares & $\begin{array}{c}\text { Degrees } \\
\text { of freedom }\end{array}$ & F \\
\hline Individuals & 0.06538085 & 0.0001816135 & 360 & $6.04^{* * *}$ \\
Side & 0.15068294 & 0.0150682942 & 10 & $501.23^{* * *}$ \\
Side x individuals & 0.01082263 & 0.0000300629 & 360 & $1.56^{* * *}$ \\
Error & 0.01429940 & 0.0000193235 & 740 & \\
\hline
\end{tabular}

$* * * \mathrm{p}<0.001$ 
components accounted for $88.2 \%$ of the total variance. For both age groups, the shape changes associated with $\mathrm{PCl}$ were mainly deformations in landmarks 7 to 9 and 10 to 12 (data not shown), resulting in the whole mandible varying in the condylar ramus.

\subsection{Procrustes ANOVA and MANOVA}

Results of Procrustes ANOVA to study the left-right variation in both age groups are given in Tables 2 and 3, and agree with those from the PC analysis. The tables show the deviations of the configurations from the consensus, decomposed according to the main effects of individuals, sides, and the individuals-by-side interaction. The consensus determined by Procrustes ANOVA indicated that DA accounted for the largest portion of the total variation, causing the variation in symmetric shape among the more subtle individuals. Since the amount of DA greatly exceeded that of measurement error, the test for the sides yielded a highly significant result with both methods. DA was especially high for "subadults". MANOVA tests (Tables 4 and 5 ) indicated that FA was also highly significant.

The permutation test for all ages indicated that the multivariate regression was statistically significant (0.693\%). This allometry can be visualised as the shape change that corresponded to an increase in centroid size (Figure 2). The allometric shape changes among the hemimandibles corresponded to landmark movements of the condylar ramus.

\section{Discussion}

The mandible is an asymmetric bone, as many results in humans show (PIERRAKOU, 1990; PONYI, SZABO and NYILASI, 1991; WESTESSON, TALLENTS, KATZBERG et al., 1994; MATTILA, KONONEN and MATTILA, 1995; GUSTINA, PENHALL and TOWNSEND, 1997; TÜRP, ART, VACH et al., 1998).

Table 2. Results of the Procrustes ANOVA conducted on the landmark sets for Sus scrofa "subadults".

\begin{tabular}{lcccc}
\hline \multicolumn{1}{c}{ Source } & Degrees of freedom & Sums of squares & Mean Squares x 10 & F \\
\hline Individuals & 210 & 0.024416 & 116 & $6.8349^{* * *}$ \\
Sides & 10 & 0.102060 & 10,206 & $599.9491^{* * *}$ \\
Individuals x side & 210 & 0.003572 & 17 & 0.2494 \\
Measurement error & 440 & 0.030001 & 68.2 & \\
\hline
\end{tabular}

Sides $=$ side-directional asymmetry; individual $\mathrm{x}$ sides interaction $=$ fluctuating asymmetry. Significance was tested with 1,000 permutations. ${ }^{* * *} \mathrm{p}<0.001$.

Table 3. Results of the Procrustes ANOVA conducted on the landmark sets for Sus scrofa "adults".

\begin{tabular}{lcccc}
\hline \multicolumn{1}{c}{ Source } & Degrees of freedom & Sums of squares & Mean Squares $\mathbf{x ~ 1 0}$ & F \\
\hline Individuals & 140 & 0.0067407 & 48.148 & $6.0408^{* * *}$ \\
Sides & 10 & 0.0508310 & $5,083.1$ & $637.7375^{* * *}$ \\
Individuals x side & 140 & 0.0011159 & 7.9705 & 0.1560 \\
Measurement error & 300 & 0.0153210 & 51.069 & \\
\hline
\end{tabular}

Sides $=$ side-directional asymmetry; individual $\mathrm{x}$ sides interaction $=$ fluctuating asymmetry. Significance was tested with 1,000 permutations. $* * * \mathrm{p}<0.001$.

Table 4. MANOVA tests for directional asymmetry and fluctuating asymmetry of "subadults". The error effect used to test the main effect of reflection was the individual x reflection interaction, whereas the interaction effect was tested against the asymmetry component of the among-image variation (replicate measurements). The test statistic used was the Lawley-Hotelling trace T. Notice that due to object symmetry, there was no test for the main effect of individuals corresponding to the univariate test because the individual $\mathrm{x}$ side interaction occupied a different subspace of the shape space for all the landmark configurations.

\begin{tabular}{lrrrr}
\hline \multicolumn{1}{c}{ Source } & $T$ & $\mathrm{~F}$ & Degrees of freedom l & Degrees of freedom2 \\
\hline Individuals & 94401.49 & $42.645^{* * *}$ & 2100 & 1801.244 \\
Sides & 81283.69 & $771.897^{* * *}$ & 100 & 942.752 \\
Individuals x side & 6087.96 & $2.757^{* * *}$ & 2100 & 1896.152 \\
\hline
\end{tabular}

$* * * \mathrm{p}<0.001$.

Table 5. MANOVA tests for directional asymmetry and fluctuating asymmetry of "adults".

\begin{tabular}{lrrrr}
\hline \multicolumn{1}{c}{ Source } & \multicolumn{1}{c}{ T } & $\mathrm{F}$ & Degrees of freedom1 & Degrees of freedom2 \\
\hline Individuals & 65347.43 & $43.086^{* * *}$ & 1400 & 1112.520 \\
Sides & 245388.60 & $2351.808^{* * *}$ & 100 & 603.082 \\
Individuals x side & 2778.64 & $1.842^{* * *}$ & 1400 & 1204.945 \\
\hline
\end{tabular}




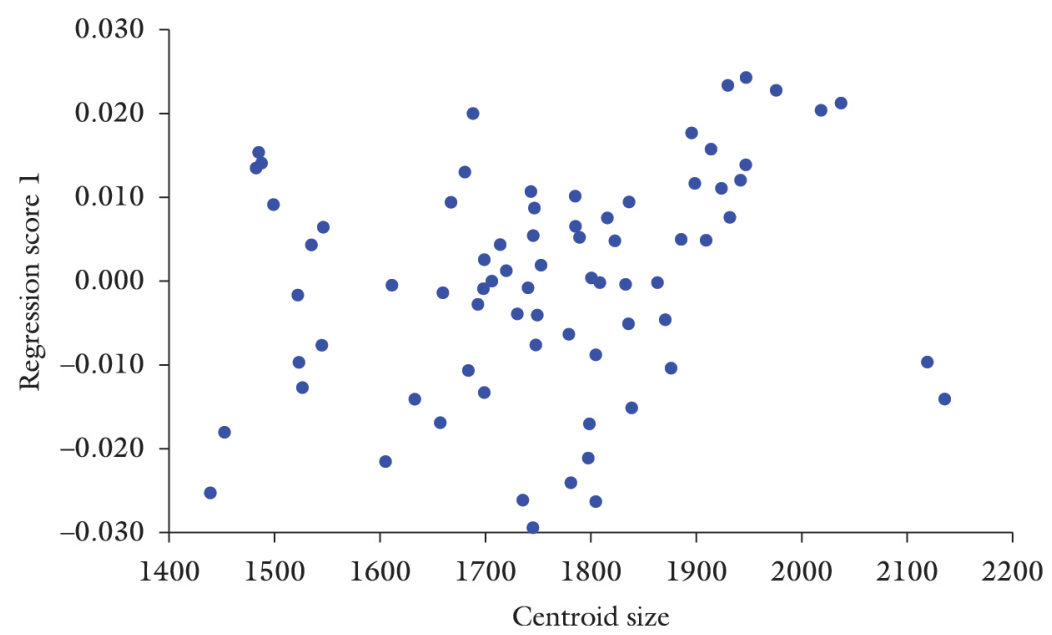

Figure 2. Shape scores obtained from the plotting of multivariate regression against centroid size.

Melnik (1992) observed a strong trend of left-to-right dominance in the mean mandibular length, but Ponyi, Szabo and Nyilasi (1991) noted that the right side of the mandible appeared to be larger than the left side slightly more frequently than vice versa. For Pierrakou (1990), asymmetry of the mandible was found in $82 \%$ of the study cases, with the right side being smaller than the left side in $47.5 \%$, but this asymmetry was different between the ramus and the corpus. As shown in Sus scrofa, the mandible is an asymmetric bone, as it is in humans, and is centred on the condylar ramus too. This could be explained by a functional and mechanical reason, as the chewing forces from the mandible to the cranium during mastication seems to be related to condylar size, at least in humans (UTHMAN and AL-RAWI, 2006). Thus, there was an effect of dentition (age) on condylar asymmetry. However, the differences between the two sides were low enough to be not clinically relevant.

The ramus, the mandibular notch and the condylar process are highly variable and probably play an adaptation role in relation to the cranial base or masticatory apparatus to maintain the symmetry of the occlusion. To support this idea, further studies are necessary, notably in foetuses, to compare the symmetry of the neural part of the mandible before tooth development and masticatory function. Our results also demonstrated that size did not change with age for the studied age period.

\section{References}

BOOKSTEIN, FL. Morphometric tools for landmark data. New York: Cambridge, 1991.

GUSTINA, SW., PENHALL, B. and TOWNSEND, GC. Morphological variability of the human inferior alveolar nerve. Clinical Anatomy, 1997, vol. 10, n. 2, p. 82-97. http:// dx.doi.org/10.1002/(SICI)1098-2353(1997)10:2<82::AID$\mathrm{CA} 2>3.0 . \mathrm{CO} ; 2-\mathrm{V}$

HAMMER, Ø., HARPER, DAT. and RYAN, PD. PAST: Paleontological statistics software package for education and data analysis. Palaeontologia Electronica, 2001, vol. 4, n. 1. p. 2-9. Available from: <http://palaeo-electronica.org/2001_l/past/ past.pdf $>$. Access in: 04/11/2013.
INTERNATIONAL COMMITTEE ON VETERINARY GROSS ANATOMICAL NOMENCLATURE - ICVGAN. Nomina Anatomica Veterinaria. 5th ed. USA: Editorial Committee, 2005.

KLINGENBERG, CP. MorphoJ. Manchester: University of Manchester, 2011. Available from: <http://www.flywings.org.uk/ MorphoJ_page.htm>. Access in: 04/11/2013.

KLINGENBERG, CP and McINTYRE, GS. Geometric morphometrics of developmental instability: analyzing patterns of fluctuating asymmetry with Procrustes methods. Evolution, 1998, vol. 52, n. 5, p. 1363-1375. http://dx.doi.org/10.2307/2411306

KLINGENBERG, CP. and SAVRIAMA, Y. Geometric morphometrics of complex symmetric structures: Shape analysis of symmetry and asymmetry with Procrustes methods. Evolution, 2002, vol. 56, n. 10, p. 1909-1920. PMid:12449478. http:// dx.doi.org/10.1111/j.0014-3820.2002.tb00117.x

LEAMY, L. Morphometric studies in inbred and hybrid house mice. V. Directional and fluctuating asymmetry. American Naturalist, 1984, vol. 123, n. 5, p. 579-593. http://dx.doi.org/10.1086/284225

LEAMY, L. and KLINGENBERG, CP. 2005. The genetics and evolution of fluctuating asymmetry. Annual Review of Ecology, Evolution, and Systematics, vol. 36, p. 1-21. http://dx.doi. org/10.1146/annurev.ecolsys.36.102003.152640

MARQUEZ, E. Sage: symmetry and asymmetry in geometric data. Version 1.05. 2008. Available from: <http://www-personal.umich. edu/ emarquez/morph/>. Access in: 04/11/2013.

MATTILA, M., KONONEN, M. and MATTILA, K. Vertical asymmetry of the mandibular ramus and condylar heights measured with a new method from dental panoramic radiographs in patients with psoriatic arthritis. Journal of Oral Rehabilitation, 1995, vol. 22, n. 10, p. 741-745. PMID: 8606331

MELNIK, AK. A cephalometric study of mandibular asymmetry in a longitudinally followed sample of growing children. American Journal of Orthodontics \& Dentofacial Orthopedics, 1992, vol. 101 , n. 4, p. 355-366. http://dx.doi.org/10.1016/S0889$5406(05) 80329-4$

PALMER, AR. and STROBECK, C. Fluctuating asymmetry: measurement, analysis, patterns. Annual Review of Ecology and Systematics, 1986, vol. 17, p. 391-421. http://dx.doi. org/10.1146/annurev.es.17.110186.002135

PIERRAKOU, E. Asymmetry of the mandible. Study of 386 mandibles in vitro. Helleniko Periodiko gia Stomatike \& Gnathoprosopike Cheirourgike, 1990, vol. 5, n. 1, p. 13-16. PMID:2130050 
PONYI, S., SZABO, G. and NYILASI, J. Asymmetry of mandibular dimensions in European skulls. Proceedings of the Finnish Dental Society, 1991, vol. 87, n. 3, p. 321-327. PMid:1749778

ROHLF, FJ. tpsDig. Version 2.10. New York: Stony Brook University, 2006.

ROHLF, FJ. tpsRelw. Version 1.45. New York: Stony Brook University, 2007.

SAVRIAMA, Y., NEUSTUPA, J. and KLINGENBERG, CP. Geometric morphometrics of symmetry and allometry in Micrasterias rotata (Zygnemophyceae, Viridiplantae). Nova Hedwigia Beiheft, 2010, vol. 136, p. 43-54.

SOLON, CCE., TORRES, MAJ. and DEMAYO, CG. Describing the shape of the face of hypertensive and non-hypertensive adult females using geometric morphometric analysis. HVM Bioflux, 2012, vol. 4, n. 1, p. 45-51.

TÜRP, JC., ALT, KW., VACH, W. and HARBICH, K. Mandibular condyles and rami are asymmetric structures.
Journal of Craniomandibular Practice, 1998, vol. 16, n. 1, p. 5156. PMID: 9481986

UTHMAN, AT. and AL-RAWI, NH. Orthopantomographic assessment of mandibular asymmetry as an aid in diagnosis of tempromandibular problems. Journal of Baghdad College of Dentisrty, 2006, vol. 18, n. 2, p. 40-42.

VAN VALEN, L. A study of fluctuating asymmetry. Evolution, 1962, vol. 16, p. 125-142. http://dx.doi.org/10.2307/2406192

VON DEN DRIESCH, A. A Guide to the measurement of animal bones from archaeological sites. Peabody Museum Bulletin, 1976, vol. 1, p. 1-137.

WESTESSON, PL., TALLENTS, RH., KATZBERG, RW. and GUAY, JA. Radiographic assessment of asymmetry of the mandible. American Journal of Neuroradiology, 1994, vol. 15, n. 5, p. 991999. PMid:8059674
Received December 12, 2013 Accepted December 5, 2014 